\title{
Study of English Teaching Model of Autonomous Learning
}

\author{
Lijun Wang \\ Hubei University of Science and Technology, \\ Xianning, Hubei, China
}

\begin{abstract}
Autonomous learning is a modern learning way that corresponds with the traditional acceptance learning. Students as the main body of learning by students' independent analysis, exploration, practice,questioning, create other methods to achieve the learning objectives.This paper analyzed the characteristic of self-learning and the theoretical basis of the implementation of autonomous learning during English teaching process focused on the College English independent study pattern.
\end{abstract}

Keyword:self-learning; teaching model; English Teaching

\section{INTRODUCTION}

Autonomous Learning, the concept was first proposed by Henri Holec, introduced in the 1980s, the field of second language teaching,independent study is the ability of learners to manage their own learning, that is, responsible for learning all aspects of the problem for decision-making. He believes that this decision-making activities is reflected in the following aspects: to determine the learning objectives; decided to learn the content and progress; to choose study methods and techniques; to monitor the learning process; to assess the learning effect.This idea is a challenge to the traditional teaching model. Some scholars have self-learning is defined as "an objective,critical reflection of the ability and the ability to make decisions and take independent capacity to act". Summary for "independent study" refers to the learner consciously identify learning objectives", develop study plans,and select learning materials content, and adjust learning strategies and their own study results make the evaluation as a learning model.

\section{Theoretical basis of implementing independent study}

Based on some important research finding in psychology,behaviorism and cognitive theory, scholars put forward to the theoretical framework of social constructivism in 1996, on the basis of students, teachers, teaching task, environment and its mutual relations and interaction during the process of learning and teaching,which has aroused widespread interest in educational psychology and linguistics. Social constructivist teaching theoretical framework used in teaching practice is a new perspective, because of its great important and emphasis on independent learning process, humanism factors as the dominant core of the learning process, respect for students' personal feelings and needs, and advocates, including cognitive and effective whole-person education. The core of the social constructivist theory is that human knowledge is not simple to teach,but by individuals construct,rather than the other pass, that is, the cognitive individual often starting from the background of their own experience, the subjective interpretation of objective things and the significance of construct. This construction in which the social environment of cognition individuals interact with one another, is the result of the individual and individual interaction, interactive.In the learning process,students construct knowledge of the maintake the initiative to build, complete teaching tasks set by teachers and understand the significance and relevance of these tasks. The entire process of learning 
in the classroom environment and the external social environment, and always affected.Therefore, students, teachers, task and their environment together constitute a balanced and dynamic system.

Constructivism theory requires students to cultivate independent thinking in the learning process, emphasizing the main cognitive role of the learner that the learner is of positive significance to the builders and problem solvers. Constructivism focuses on the improvement of learners' cognitive level, emphasizing the learners to actively participate in the process of meaning construction under the guidance of teachers. College English teachers should use variety of teaching methods to enable students to actively construct understanding of the language to teach students learning to help students self-learning, cooperative learning.In accordance with the theoretical perspective of constructivism, learners' autonomous learning teaching methods should be a linear relationship between the teachers to create problem situationAutonomous learning - learners cooperative learning group discussion(sub)-learning evaluation. In order to promote the development of learners' autonomous learning ability, teachers should be appropriate to adjust their teaching strategies and targeted to impose the teaching impact.

\section{The transition of consciousness is the premise to}

\section{carry out self-learning model of the college of the}

\section{College English}

In the new learning model,the targeting of college English teaching has changed:the change from the traditional to teach students knowledge to teach students learning ways, that is, from the need to learn to "change" will learn. Teachers should not only enable students to proficiency in listening,saying,reading,writing and translation skills, but also to teach student learning a foreign language strategy to become independent learners. Therefore,the concept of teachers teachers teaching and students learning should radically change. Reflected in the teaching model,the teacher student "substitute teachers from the classroom commander and leader to guide and organizers, students form passive" spoon-feeding type learn to change the practice of learning and experience. 3.1 The changing role of self-learning mode of the College English teachers.

We follow the teaching philosophy of the main teaching in the traditional English teaching. In the traditional college English classroom teaching, teacher classroom activities, the teacher is both a source of knowledge disseminators, or the students' classroom learning activities of supervisors and managers while students in a relatively passive role and become the one that all ideas are instilled into his mind. Over the years, the teacher conducted classroom of students listening to teacher-centered teaching model that has been entrenched. In this way, student will lose the enthusiasm and initiative to learn; a serious lack of motivation to learn and interest in learning; students to teachers, there is a considerable dependence, resulting in independent learning ability of a decline. This teaching model and role are contrary to College English Curriculum Requirements, Promote student-centered self-learning model, changing the role of teachers is imperative.

3.2 Students need to raise awareness of autonomous learning.

Constructivism holds that knowledge is not static, knowledge is constructed by the learner in the process of specific learning activities based on their experience background is not a passive replication-learning,learners need to carry out reprocessing and re-creation in order for the original knowledge the specific questions the solution. Learning is not a passive receiver of information to stimulate but take the initiative to construct meaning. Only when people figured out how to learn, learn to strain and self-regulation can be called by education. Students in independent study should enable students 
to understand that he is actively involved in independent study of the protagonist, have to reanalyze their own, clear positioning of their own role in the independent study, and the need to grasp the situation to establish learning objectives according to their actual knowledge,develop study plans, to construct new knowledge through self-learning way.

With the rapid development of science and technology and the popularity of the network on campus, the mere knowledge of curricular increasingly unable to meet the learning needs of students. You need in a timely manner as university teachers to understand the latest teaching reform, teaching, information and teaching dynamic, With the influx of network knowledge, and expand student' knowledge.Thus, teachers themselves need to become independent learners,so that they have the guidance, organization and teach students knowledge, skills. At the same time, the research capacity of the Learners Autonomy of teachers also put forward higher requirements, only to improve the research capacity to adapt to new requirements for teaching reform.Focus on the development of college English teachers and scientific research ability,the majority of teachers and students will benefit.University teachers, research papers,and research projects and so on college English teaching, especially students' autonomous learning ability and training, and provide theoretical support. So, teachers only improve the self-knowledge and ability that they have enough knowledge to teach students to adapt to the development of new teaching model.In addition, teachers in addition to through observation, between the universities abroad for training to improve their abilities,must also be obtained through a variety of ways students feedback based on students' responses,to integrate their teaching plans; an open mind to other old teachers consult more than lectures, discussions, and more to listen to opinions and suggestions of, the old teachers.

\section{IT and network to learn on their own learning}

With the raid development and wide application of the computer internet technology, today's college English teaching is inseparable from the computer Internet.Under the guidance of the leaner as the main ideological, college English autonomous learning increasingly supported by hypertext link network environment learning service system through the Internet and online audio and video media playback, sharing of resources and interactive learning. This knowledge and information is extremely rich simulation language environment, the students according to their actual level and needs, since the initiative in devising and implementing suitable for their own learning strategies and exploratory manner, experiential learning English, and human-computer interaction to get instant feedback in a timely manner to adjust the learning program, learning content and learning strategies. In summary, the College English in the network network environment ,independent learning is a learner as the main mode of learning, to give full play to the initiative and creativity of learners.

Many colleges and universities are a number of self-learning software installed for the College English, but in many cases, supporting the limited network resources, and the form of rigid, no to update, resulting in students' online learning can only be shorter interest in learning a little time long to produce weary; hardware, many schools can not provide adequate free-on opportunities, students in the dormitory can not log in online learning, computer time can not be guaranteed. Some schools even often a network failure, resulting arranged lesson plans to be implemented, waste students time. The above factors so that students can not freely access the learning and thus disappointed supporting facilities of the school. Response to these circumstances, the school should on the one hand to increase capital investment to improve network facilities to enable students to increase opportunities for access to the Internet, the rational use of school 
resources; on the other hand, universities should devote more human resources, send professionals in a timely manner to maintain and update the network and software. On the other hand, it also launches the teachers and students work together, according to the different needs of students outside school hours to search resources, teaching resources to expand and reasonable classified achieving students share, increase their motivation to learn.

\section{Constructions of College English Autonomous Learning Model}

5.1 Formulate effective independent learning strategies

Formulate effective independent learning strategies, and improve learning outcomes individualized teaching to respect the students' interests, hobbies, and feelings, attitudes, and to give full play to the strengths of their students, and to tap their inherent potential to the ultimate, then you need to find the most suitable students' independent learning strategies. Effective learning strategies refer to contribute to language learning, learning and behavior. Students also are willing to learn the motives and interests of the English on the basis of learning strategies to improve learning outcomes. Allow students to adhere to write learning week in mind, and constantly reflect on their own learning concepts and learning strategies. Through summarizing what have learned knowledge of content this week, combing and review points, difficulties and mistakes in the exercises, self-reflection to learn this week to 'get' and 'loss' to explore the learning skills and strategies.

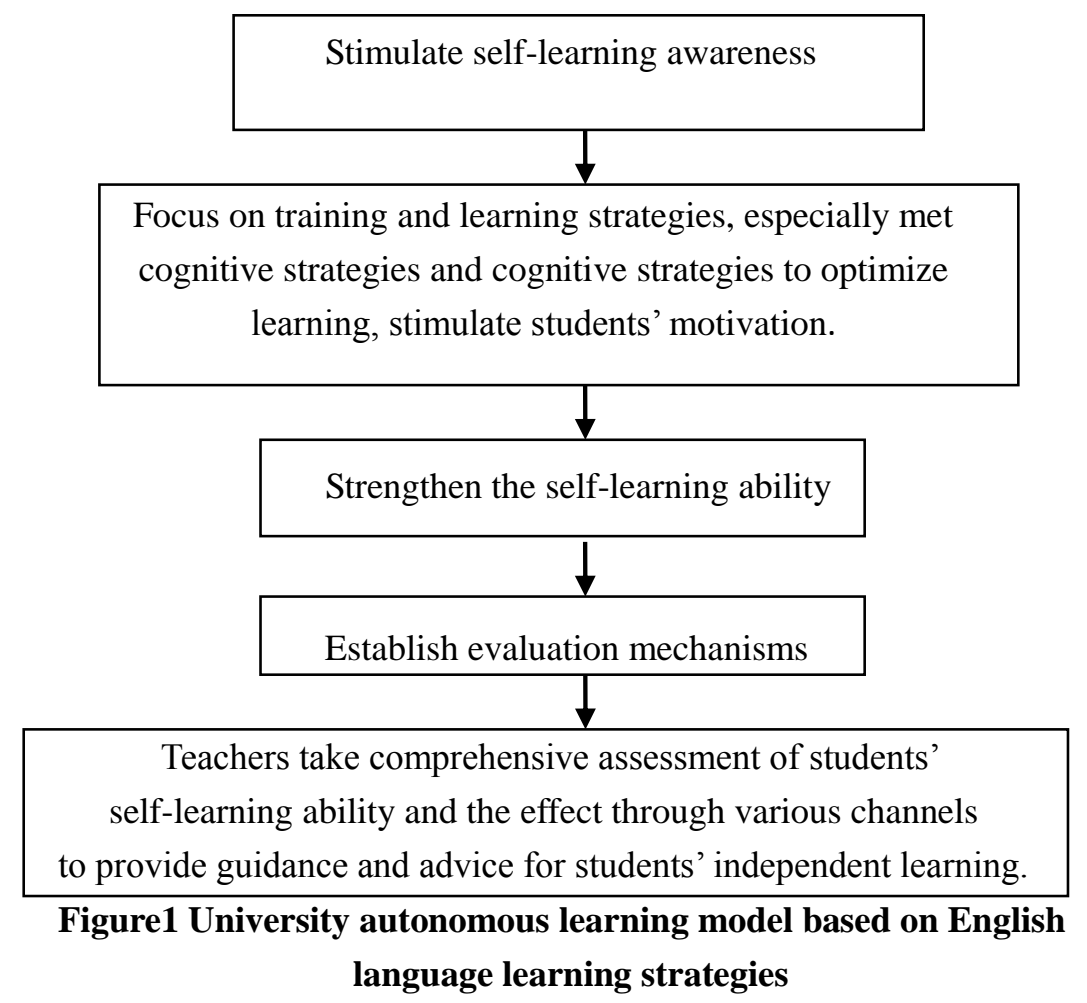

5.2 Develop awareness of independent learning

Develop awareness of independent learning, and guide students to correct attitude towards learning
English. "The first step of Autonomous Learning is the cultivation of student self-earning awareness and motivation." Many students are at a loss as to what to 
do face college English teaching as they are in the habit of listening to the teacher arrangement of primary and secondary education; they tend to think, much less learned in high school a semester in one year of college English learning.faced with this situation, they are prone to negative burn out emotions;such emotions can easily affect the students' confidence in learning English.Therefore, teachers should be timely to develop students' awareness of autonomous learning,enable students to determine the students aware of the characteristics of college English teaching,as in the secondary school classroom,only master teachers to teach some of the language point, University of autonomous learning process is particularly important.And many other subjects, learning English is not an overnight thing; it needs some time to accumulate and precipitation. Only when the students come to realize that the independent study on the importance of learning English,in terms of ideology, independent study as part of the college English learning, the learning habits will change, really pay attention to autonomous learning,the initiative to develop independent learning habits.

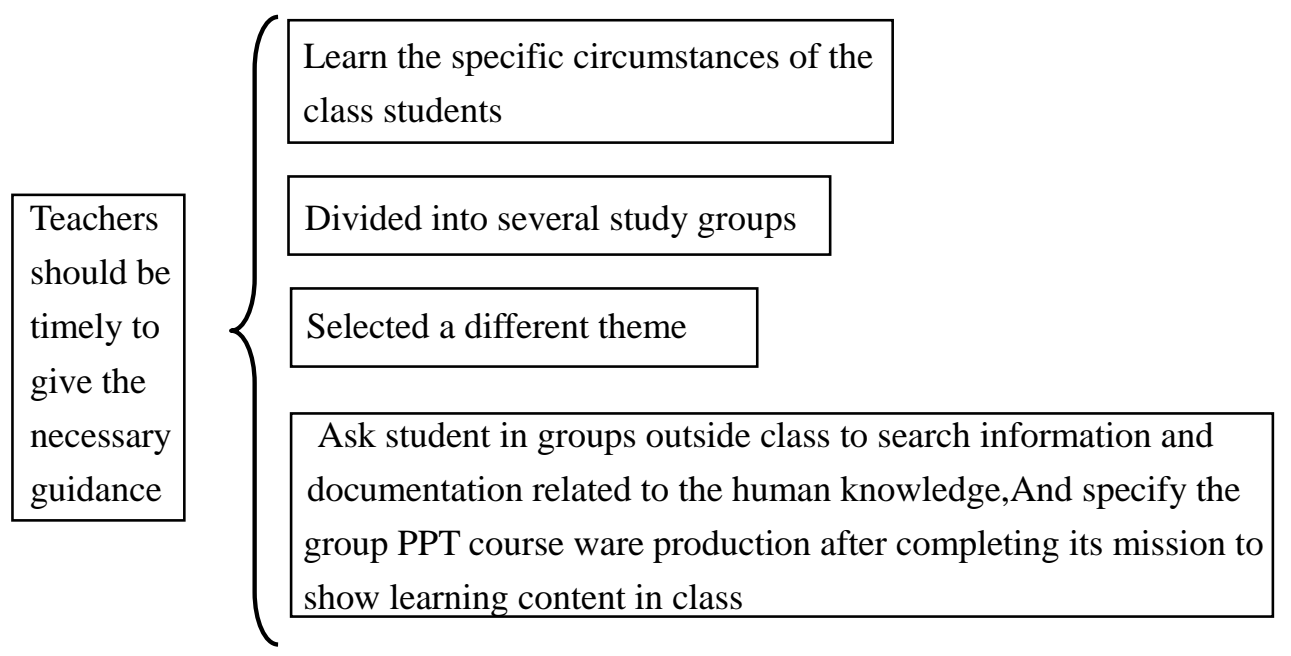

Figure 2 plan to teach text Autonomous Learning Model

\subsection{Stimulate students' own interest in learning}

Motivation is divided into intrinsic motivation and extrinsic motivation. Extrinsic motivation refers to the students to be subjected to promote, not subjective factors at work. The behavior of students is based on the purpose of a tool type; intrinsic motivation refers to motivation to meet within the activity, it does not need outside incentives, punishment to the action to the target, because the action itself is a driving force, namely foreign language learning itself can stimulate students' interest and pleasure .Held by the intrinsic motivation of students learning English is the pursuit of a goal. A strong interactive relationship between intrinsic motivation and independent learning: on the one hand, intrinsic motivation can be given self-learning behavior to power, to promote independent learning, independent study basis; on the other hand, independent study to give students more freedom of choice space, can stimulate students' intrinsic motivation to learn, and thus stimulate the self-interest in learning. The Stronger students are interest in learning English, the stronger students' initiative and consciousness and the better effect of the independent study.

5.4 Help students develop independent learning habits

Good study habits are very important for the 
culture of self-learning ability. Independent learning ability start from the habits, such as preview ,review after class. Understand the student's preview for the preview, teachers should be checked in time, so allow them to collect a lot of information related to the content of the text in the preview process, making it a truly autonomous ability to learn. For review after class, teachers can ask students to the knowledge learned to sort out the formation of knowledge structure.

5.5 Help student determine the learning objectives,develop student plains

First, let student make a clear goal during their university, then,teachers guide students to identify their level of English which help student understand their learning needs, priorities and difficulties, and finally guide student to develop short,medium and long-term goal of learning English.So student will be able to actively study.Moreover, plans are to be adjusted according to emerging.

5.6 Encourage students to conduct self-monitoring and self-evaluation

Evaluation into the learning process,you can optimize the learning process accelerator. Teachers in the autonomous learning process can be evaluation by testing students' learning behavior, process and effects access to teach feedback to improve teaching and learning model, strategies help students adjust and the learning efficiency,and achieve good learning results.The so-called self-monitoring refer to the plan of learners on independent learning activities, evaluation, feedback,regulatory activities,including the formulation of the learning data,learning strategies and methods of adjustment,as well as introspective refection on the learning process.Though these means,students can fully understand their own learning situation,the timely detection of the problems in the study and help guide them to develop the next stage of learning objectives and plans,and applying appropriate learning strategies to these goals and plans into practice.Teachers learning the required height to stand in the general language to help student effectively monitor their own learning process and learning to make objective and true self-evaluation, which has a strong role in promotion learners autonomous learning ability.

\section{CONCLUSIONS}

In the Chinese cultural environment, to promote independent learning, teaching practice according to the different environment, consider the learners' language abilities and self-learning ability to build the implementation of the program. Independent learning needs certain conditions, which,first and foremost a psychological condition .College English teachers have to change the traditional teaching concepts for independent study and research on the basis of in-depth understanding of the Chinese cultural environment, based on classroom teaching .Furthermore, we must always guide the students to change their ideas, and constantly improve their own sense of learning and ability as a primary task, while changes the of students to enhance their awareness and ability, not primarily by preaching but by the guide. At the same time, college English teachers require a certain material conditions to implement the self-learning. To change students' ideas, develop their self-learning ability require a more lengthy process. The process of cultivating students' independent learning ability, teachers should find out the root of the problem and put forward to appropriate measures that are directed against students' puzzle, confusion and conflict, thereby contributing to the effective conduct of the English self-learning model.

\section{References}

[1]Ge Yuhe.On-Line Self-Access English Learning Center. A Platform

for Individualized and Autonomous English Learners[J]. Beijing Management College of Politics and Law Journal, 2005,01.

[2]LU Feng-xiang,GUO Jing, HUA Yao, YANG Bo.Medical Students' Use of Learning Strategies and Its Effect on the Development of Their 
Autonomous Learning Ability[J]. Northwest Medical Educatinon,2010,01.

[3]BAI Gui-fen. An Investigation and Analysis of Non-English Majors Autonomic Learning[J]. Journal of Jiaozuo Institute of Technology, 2005,04.

[4]GU Feng, CHEN Wen, KE.Ying-gen.Research Into Construction Of The Systenm Of The Formative Assessment For Multimedia Network Autonomous Learning Of College English[J]. Journal of Chaohu College,2011,04. 